\title{
BALANCING OPERATIONAL AND STRATEGIC IMPACTS ON INFORMATION MANAGEMENT
}

\author{
Diana Malvius* \\ Royal Institute of Technology \\ Stockholm, Sweden
}

\author{
Dag Bergsjö \\ Chalmers University of Technology \\ Göteborg, Sweden
}

\author{
Sara Molneryd \\ Royal Institute of Technology \\ Stockholm, Sweden
}

\begin{abstract}
Strategies for successful information management that supports multidisciplinary systems engineering are reported on. Interdisciplinary and inter-lifecycle integration are considered as prerequisites to establish efficient information management. Top and middle management, and designer perspectives on integrated information management have been studied in an interview study within electrical and electronics, and software R\&D departments in the automotive industry. Identified misalignments in needs, expected benefits and goals for information management between different perspectives are described. Ways to achieve synergies and conflicts with operational and strategic impacts on information management are discussed in the paper.
\end{abstract}

\section{INTRODUCTION}

One critical area in order to improve efficiency in complex product development is information management. In the automotive industry, the need to share information throughout the entire systems engineering (SE) process is extensive. Due to differently structured and visualized information, designers have a recurring task to gather and sort information in their everyday work. Increased product complexity and shortened time-to-market stress the need for information to be transparent, accessible and managed by management and designers from different engineering disciplines. It is suggested that information flow is necessary for collaboration between engineering disciplines as well as through the product lifecycle, feeding downstream processes (Figure 1). Collaboration i.e. mutual understanding, collective goals and shared resources, is necessary for interdepartmental integration [1], and the same approach is taken in this paper for interdisciplinary (within R\&D) integration. Inter-lifecycle integration, i.e. handover in the product development process, is made complicated by for example heterogeneous requirement specifications and information refinement where handovers often are done with little understanding and no feedback of the subsequent stages (e.g. when a CAD drawing is changed by a manufacturing engineer to be easier to produce, a particular function important to the original designer is lost). Integration depends on both organizational and technical enablers. Barriers to information management can be behavioral, process-related or organizational [2]. Turesson [3] describes a framework for integration of IT infrastructure, applications, information, methods, and processes. Integration challenges throughout the V-process (Figure 1) are discussed in research on complex systems reported from e.g. the aerospace industry [4] and automotive industry [5]. The benefits of a new system or process come true on a large-scale plan if people and organisations realise the significance of the project and change their way of thinking, and start operating in accordance with the new models. To promote change reasons for it have to be shown. Designer commitments are directed by needs, values and beliefs. The values of the company should be in harmony with individual values so that commitment is regarded as sensible [6].

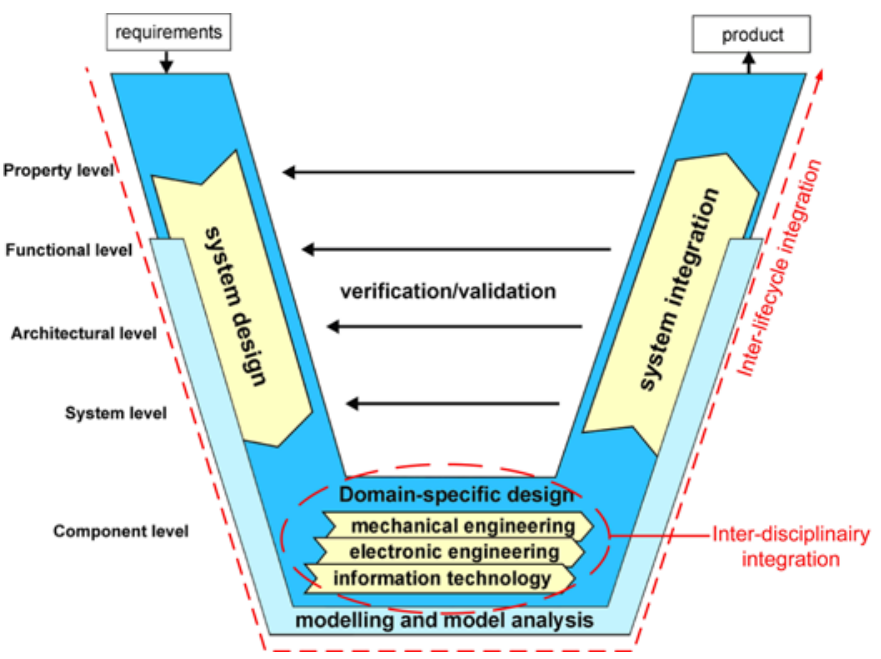

Figure 1. The systems engineering process (after VDI 2206) used at the studied company. Inter-disciplinary and inter-lifecycle integration is illustrated in the figure.

\footnotetext{
* Corresponding author.
} 
Information management for electrical and electronics (EE) and software development is discussed in particular in this paper. The engineering domains of e.g. mechanics, electronics and software need to be more aware of each other's development problems and needs in order to achieve efficient inter-disciplinary information exchange [7]. The same understanding for integration is needed inter-lifecycle in the SE process.

\section{RESEARCH APPROACH}

In practice, when information management efforts are made in organizations, focus in industry often is on technical challenges with information systems (IS) such as interface definitions and information modeling, and how IS are going to be introduced in the organization $[5,8]$. The approach taken in this paper is that organizations have to make both organizational and technical adaptations to achieve interdisciplinary and inter-lifecycle integration. Operational measures are expected to be important for designers that experience practical problems connected to information management, while strategic measures should be of value for management. Hence, the two integration aspects are approached from both an operational designer and a strategic management perspective.

The purpose is to define means to achieve better interdisciplinary and inter-lifecycle integration in information management for SE. Similarities and differences between designers and top and middle management with experienced needs, benefits and goals with information management are explored in this paper. Misalignments and conflicts as well as synergies are explored. It is discussed what implications the findings have on efficiency in information management. The following research questions (RQ) are stated in order to reflect both operational and strategic perspectives:

RQ1: What are the experienced needs with integrated information management?

RQ2: What are the expected benefits with integrated information management?

RQ3: What are the goals with integrated information management?

\subsection{Case Study}

A case study, that took place during spring and autumn 2006 in the EE and software departments of a car manufacturer, is reported on. The case study was designed to compare management and designer perspectives regarding information management within the EE department. For the context of this paper, information management refers to the way product related information is managed within the company. This is done through for example meetings, telephone calls and IS (Figure 2). Within the context of IS several systems are currently used at the studied company; product data management (PDM) and product lifecycle management (PLM) systems are central for this study.

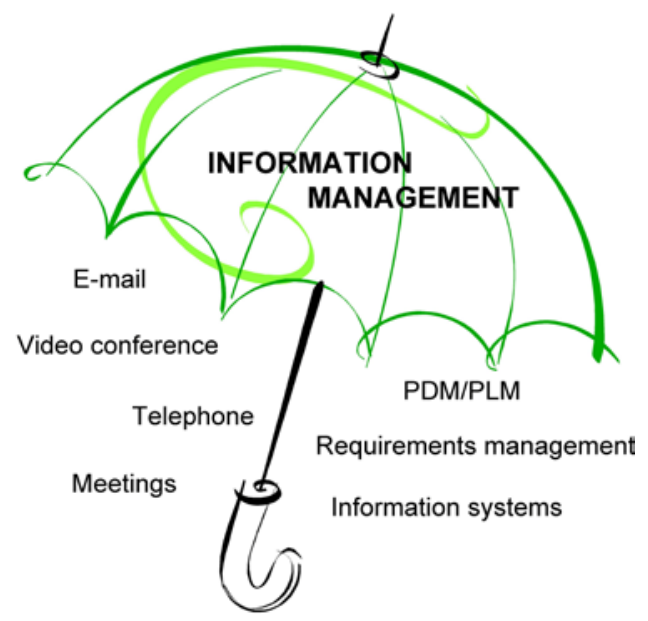

Figure 2. Information management consists of different activities for retrieving, storing and sharing information.

The study is part of a larger research project, performed within the same company, regarding information management in complex product development [7, 9]. Company initiatives to achieve integration of information started some years ago in the company by EE and software designers. The overall project foci are on the shift from textual requirement specifications towards model-based and object-oriented ways to manage EE requirements. Collaboration between industry and academia enables the researchers to take on different viewpoints and unit of analysis in the case studies, and make comparisons between the different studies. Longitudinal research provides the researchers with material that enables analysis and comparisons that include organizational and technical changes.

\subsection{Methodology}

The applied research process consisting of three main steps; findings, analysis and evaluation, is described in Figure 3. Interviews were chosen as data collection method to qualitatively describe the situation and the respondents' view on information management, and to gain a better understanding of the informal connections between different organizational layers. The interview questions focused on the way information is managed in the SE process and what the perceived goals and benefits with information management are according to top and middle management, and designers.

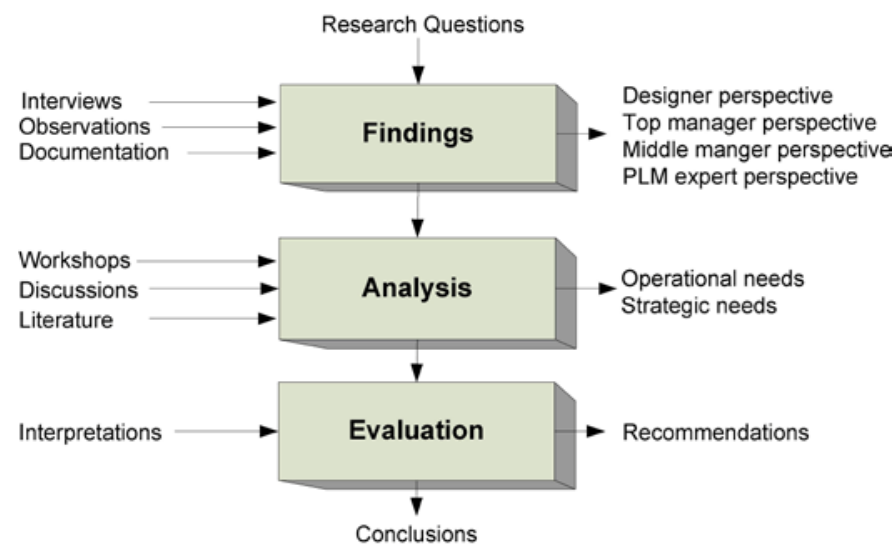

Figure 3. Applied research process. 
Semi-structured interviews lasting on average one hour were performed. The interviewees were selected by initial contacts and recommendations, but also on random based on the respondents departmental belonging and organizational function. To be able to compare the results hierarchically in the organization, the respondents were selected from five different organizational levels within R\&D EE and software departments. .

A total amount of 27 interviews were performed. Four top managers including the head of EE R\&D and nine middle managers were included in the study. Twelve designers were interviewed of which five belonged to the mechanical department. They were considered control interviews in order to compare mechanical and EE needs for information management. In addition, two PLM experts involved in global PLM projects within the company were included in the interview group due to their knowledge and experience about earlier and current company initiatives within the PLM area. One of the PLM experts had more than 30 years of experiences from PLM, PDM and IT support for product development.

Top management and PLM experts are categorized as not being main users of IS, whereas middle managers and designers are considered to be main users of IS. Middle managers need interfaces towards the IS and could be regarded as IS user in the sense that they need to verify and control information in the IS. Designers are the only category actually authoring product information stored in the IS.

\section{FINDINGS}

Findings are presented grouped according to organizational belonging; top management, PLM experts, middle management, and designers.

\subsection{Top Management Perspective on Information Management}

Top management regards the use of standardized SE processes as the main approach to achieve integrated information management. Deviations from the prescribed product development processes are considered one of the main reasons for inefficient information management.

According to top management, another reason for poor integration of information is insufficient IS. Top management regards IS mainly as a means for SE, where information exchange for system design (Figure 1) is possible, enabling inter-disciplinary integration. When implementing a new IS, top management stresses the importance of contracting IS suppliers that can perform the introduction and customization projects of IS in a short time, and that can support the company with personnel at development sites globally. It is also considered important that the IS supplier has experience of working with large companies as well as being financially solid, so that long-term commitment can be assured.

When asked about organizational change projects compared to product development projects, top management do not feel that there exist any differences in carrier opportunities or funding. From a top management perspective IT/IS projects have received both relatively high funding and manpower. One reason for the importance of these issues is that the EE department at the company is the centre within the larger group for EE development, and is hence committed to develop IS for EE that should be used globally within the corporation.

\subsection{Expert Perspective on Information Management}

Experts find that designer requirements and needs stated on information management are very difficult to manage in practice since focus often is on operational and highly specialized issues, such as performance problem and lead times. Today there is too much of territorial disputes among system owners, management, and engineering disciplines. This in combination with a short-term operational focus makes it difficult to achieve SE improvements. According to PLM experts, designers must focus less on their development tasks and realize the trade-off between standardization and specialization. The respondents claim that in order to effectively gain support for new and much needed radical improvements to management of information, a change in mindset is necessary. A new mindset must include a philosophy that the systems are more important than the individual components of the product. Development must be seen more as a teamwork where product, factory and other parts of the company are integrated parts that contribute to the progress of the company.

Pragmatic bottom-up projects have successfully solved problems with IS from the designer's perspective, but what they managed to solve locally for a specialized group have later failed because the solutions were not scalable to a broader set of users. According to interviewed PLM experts an acceptable trade-off between user needs and technical challenges is highly integrated IS solutions where the IS users have to adapt their work procedures. According to the interviewed PLM experts there is a discrepancy between existing work procedures and what the used IT applications actually are able to support. The current scope of PLM at the company is limited to CAD and PDM integration.

Interviewees stressed that it has been difficult to assure funding for projects that basically are about integration of processes and method into the PLM system solutions. IS introduction and roll-out projects are favored by the company culture, while projects that aim at improving the organization are not highly funded.

\subsection{Middle Management Perspective on Information Management}

Current problems in EE and software development, such as not updated requirements, inefficient search for product data etc are recognized by middle management to be caused by poor information management and inefficient IS. Middle managers have a background in EE development and claim to have a good understanding of the engineering possibilities and limits within these departments. They realize that designers are forced to manage problems inconsistent and recurring requirements due to multiple information sources. The improvement of the information management procedures and overall structure of the SE processes is seen as a main improvement area by middle managers. Middle management also stresses the need to integrate information across 
disciplines and to achieve a system integration view when managing information. It is believed by middle managers that this might be obtained by a comprehensive IS that manages inter-disciplinary work tasks and information.

In line with top management, middle management also brings up the need for better inter-disciplinary integration to improve information management. They experience that early EE involvement in the development process in reality is followed by a period of numbness before late process re-involvement. This has an effect on the company motto "doing things right the first time"; suggesting early collaboration from all concerned parties involved in SE to minimize the need for late changes. Though, respondents state that if this is going to be true for EE and software development, operational support for improved efficiency is required, to promote continuous interdisciplinary involvement throughout the SE process.

Middle managers experience that top management primarily focuses on short-term outcomes. This is reflected on in current regulations for promotions and bonus systems. Investments that are easy to connect with improved quality and lower cost are favored instead of change projects that in a longer time span might have larger benefits. This is in particular true for change projects regarding information management and IS. A majority of the middle management point out that they have to struggle for getting funds that are earmarked for improving EE information management.

\subsection{Designer Perspective on Information Management}

Designers focus on operational (short-term) problems with information management, and the overall experienced inefficiency in product development due to slow information retrieval and inefficient requirements management. There are no standard formalized ways of creating product information (in particular requirements) and there are many tools that are used for managing the product information. E.g. text editor is the most frequent tool for creating requirement documents and Word makes it possible for designers to state requirements that do not follow a particular standard or template. Designers state that most important in product development is to meet goals and deadlines, and to not fall behind in the schedule.

According to the interviewed designers a major part of the daily work is spent on managing information. The retrieving, storing and searching for information takes too long time from the designers other daily work tasks. Current IS are insufficient and require a lot of unmotivated work. IS performance and lack of process support are major problems of the legacy systems. Still the interest for a new IS is rather weak, since designers expect that specific functionalities that they use in the legacy systems will be removed in new standardized systems. To further add on this, the designers do not feel that they can trust the information; some information might be missing or if it might just have been updated without the knowledge of the designer.

Designers experience that they are in need of domain-specific IT tools and are afraid that a new IS will only lead to that one additional IS. The overall attitude among designers is that the introduction of a new IS basically would imply learning one additional system, without replacing older systems. For example the mechanical designers experience a newly introduced IS (PDM system) primarily as a necessity that enforces proper use of the new CAD tool.

The need for EE to be involved early in the SE process in order to influence the overall design, e.g. chassis design is expressed as a great need by EE designers. However, according to interviews made with $\mathrm{EE}$ and mechanical designers this is a need that often is difficult for mechanical designers to realize. Lead times in EE are perceived by the mechanical designers as being shorter than in mechanical engineering. In combination with that EE design is often late and always changes just before product launch, makes this integration a major problem.

\section{ANALYZING DIFFERENT PERSPECTIVES ON INFORMATION MANAGEMENT}

Three gaps with information management have been identified from the interview study. The gaps regard needs, experienced benefits and goals with information management.

\subsection{Needs with Information Management}

In general, the studied management levels focus on strategic needs in the organization, inter-disciplinary development and the product development process, as well as platform development and higher efficiency when developing new products. Their focus and commitment is on assuring good product quality through formalized processes. When it comes to problems in information management their main interest lies in IS, e.g. different commercial IS and IS suppliers and their perspective advantages. Since top management is in charge of the budget focus is on time and cost. If organizational change improvements are difficult to measure, the funding of the projects are restrictive. The main needs analysed from a management perspective are stated below:

- higher commonality

- $\quad$ standardized IT/IS environment

- $\quad$ shorter lead-times

- frontloading PD

- higher quality

- interdisciplinary work

- lower cost

Analysis shows that most designers have gotten used to the current work conditions and accepted that information management is a problem that rather is managed by e.g. a telephone call than a search in IS. The designer needs regarding information management focus on support for individual work procedures, and improved disciplinary IT/IS functionality. The designer needs tend to be narrower than the managerial especially since EE designers tend to handle a lot of product information which means that access to reliable and updated information is important. Needs common to designers are listed in the following:

- domain-specific IT tools

- more core design work

- efficient information retrieval

- $\quad$ structured information

- data integrity

- $\quad$ earlier testing 
Based on the findings and the analyzed management needs above, it is concluded that top management main need towards information management is reflected in support for interdisciplinary and inter-lifecycle integration. Middle management experiences that the operational need for efficiency is greater than the strategic need for integration and do agree with the designers' urgent need for higher efficiency in their everyday work. This results in a gap between top management, and middle management and designers (red pyramid in Figure 4). Further it has been remarked that the term "integration" is not explicitly mentioned by designers during any of the interviews. From a designer perspective, integration problems and problems with SE are related to the closest proximity of the designer, regarding the own development group or shared interfaces. In other words, designers focus on needs with inter-lifecycle integration only in cases where they are involved or affected themselves.

\subsection{Expected Benefits with Information Management}

Support for individual work procedures against support for systems engineering is identified as one gap when it comes to experienced benefits with information management (middle pyramid in Figure 4). Top management articulate that problems with information management are due to a lack of integration, since it is argued by top management that there are more similarities in work procedures than differences it would be possible for users to get used to a standardized interdisciplinary IS. Top management tends to see information management as a means to achieve an efficient interdisciplinary SE process. Their focus is directed towards strategic issues and collaboration aspects involving several engineering disciplines. Middle management has a relatively large understanding of the problems described by the designers regarding information management. The expressed benefit with information management is not different from top management's in the sense that information management primarily should give support for SE. Designers on the other hand experience a need for improved efficiency in design work. According to the respondents, inefficiency is caused by lack of routines in information management and extensive administrative tasks. Their main benefit with a new IS would be gain of better support for existing work procedures.

\subsection{Goals with Information Management}

The gap regarding the goal with information management is between top management that focuses on overall issues such as quality and costs, and middle management and designers that have a narrower goal with information management and have requirements managements as a goal (right pyramid in Figure 4). Designers relate to information management as a possibility to get higher support for their domain or role specific work tasks to make their work more efficient. Their goal with a new system would be mainly to support their daily work situation, which in many cases includes an unacceptable amount of information management activities, in particular requirements management. Designers and middle management focus on the issue of information management in itself, and that this is difficult to solve by the introduction of a new IS. Middle management has a good understanding about the daily problems that designers encounter. There is however little knowledge among the designers and middle managers of what the top management strategy and goal for information management is. Top managements generally express goals that are rather common in particular lower cost and higher product quality. These goals are perceived as vague especially by designers since the connection between inefficient information management and cost and quality is difficult to realize, especially in comparison with more concrete design work.
NEEDS WITH

INFORMATION MANAGEMENT

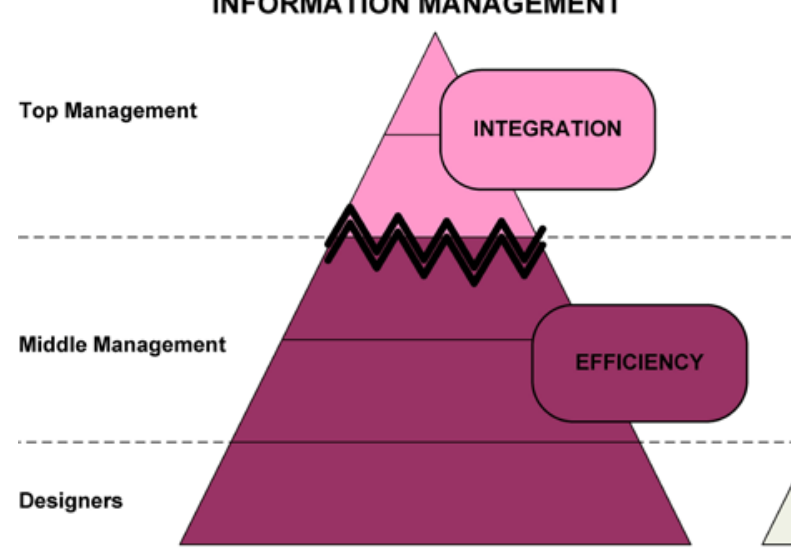

BENEFITS WITH INFORMATION MANAGEMENT

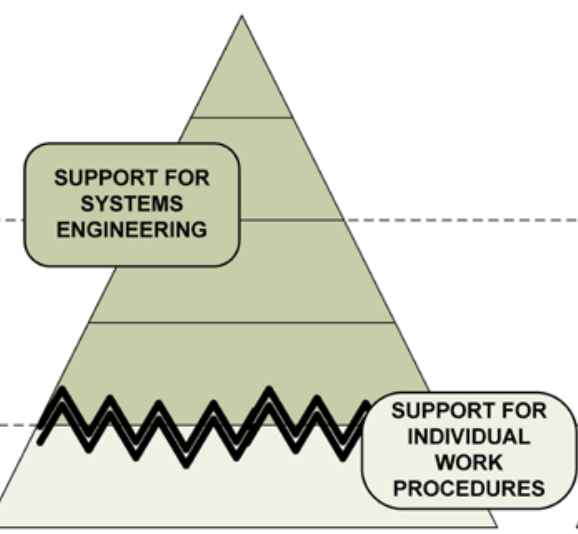

GOALS WITH

\section{INFORMATION MANAGEMENT}

Figure 4. Illustration of identified gaps with experienced needs, benefits and goals with information management. The pyramids represent the organizational levels of the EE organization, and the zigzag patterns illustrate where the identified gaps are located. 
Table 1. Designer needs stated in the matrix reflect efficiency needs in information management (left pyramid Figure 3), while management needs relate to needs for integration in information management. Green boxes indicate non-conflicting needs and point out synergies between possible benefits with integration of information. Red boxes are seen as conflicting management and designer needs that are hard to manage and find a solution to.



\section{DISCUSSION}

In this chapter ways to balance different needs, benefits and goals are discussed. This chapter focuses on the underlying needs in order to understand the different perceived benefits and goals. In center for this chapter is the strategic management and operational designer conflict as illustrated in figure 4. Middle management is not discussed separately.

\subsection{Operational and Strategic Needs}

Identified differences when it comes to information management can be illustrated as organizational gaps (as in Figure 4).I It is also possible to identify similar needs and to express synergies in the term of benefits reflecting both management and designer perspectives. In Table 1, identified discrepancies and synergies with designer and top management needs are illustrated. Table 1 is designed as a decision matrix, where each horizontal, designer need, is matched towards vertical, top management needs. Positive synergies are marked green, and negative discrepancies are marked red. A lighter color represents that the connection is weaker, and when a connection could be both positive or negative this is marked with a combination of red and green. Fields where now connection has been found has been left white.

Several synergies can be identified in the matrix, as for example in the case of $5 G$ where the designer need of data integrity is matched towards the managerial need of higher quality. Data integrity ensures the correctness of information which is a prerequisite for designing a product with the correct quality. Conflicting needs has been identified for e.g. 1B that regards user need of domain-specific tools vs. management need of standardized IT/IS. In reality this is extremely difficult to gain and would require costly investments.

Arguments (complete rows A-E or columns 1-6) that gain a high amount of green and a low amount of red are considered good arguments from both perspectives and are of such character that there are no organizational difficulties in order to solve them. There is no conflict between designer and management needs for these issues. These are in particular "efficient information retrieval", "structured information" and 
"higher quality". Management and designer needs that are in conflict with each other are regarded as bad arguments to use when promoting efforts in information management. These are in particular, "more core design work", "Domain-specific IT tools", and "lower costs". This shows the importance of management to express the needs for information management investments in terms that is beneficial for the organization and that motivates the designers. If management should go out with the business need to shorten lead-times, as the main need for PLM investments then many designers would be pessimistic towards the PLM initiative since they would connect the need of shorter lead-times, to higher work loads during a shorter time span, which is not in their interest.

According to Table 1 adaptations have to be made to the IS and/or to current IT tools in order to achieve both standardized and domain specific IT/IS (1B in Table 1). If standardized IS solutions should be used changes to current work procedures are needed. On the other hand if domain-specific IT tools are favored, tailor-made IS solutions are needed and unchanged work procedures are possible to maintain. Reflecting over Table 1, the column "domain-specific IT tools" introduces the largest amount of conflict into the matrix and this issue is also very difficult to manage in large IS introduction projects. It is argued that customized systems adapted to specific needs and organizational roles have to be compromised in favor of standardized IS. In doing this it is important to stress that this measure has to be motivated to the designers and promoted by using the benefits stated in Table 1, such as "efficient information retrieval" and "availability of structured information". It is argued that the preparations and introduction processes, rather than unique tools and systems should be adapted and customized. Thus, adapt the information management environment and not the IS to the designer needs. In this way it becomes easier to gain designer acceptance as they can perceive the situation as being adopted according to their needs, but it is still possible to use a standardized IS.

There is however problems that appear to be green in Table 1 have not yet been solved in reality. Firstly there might exist conflicting needs in other dimensions, as illustrated in figure 4. In Figure 4 the gap between strategic and operational needs is illustrated with an arrow. The length of the arrow shows the potential size of that gap. Where the views on a problem are similar the gap will be very small, and easy to bridge. Where large gap's exist (red in Table 1) it is difficult to find solutions that fulfill the needs from both perspectives, and some sort of compromises or trade-offs are necessary. Problems might be connected to other challenges, such as technical needs e.g. the system supplier does not provide a suitable solution. Secondly these problems have not been dealt with due to that there are conflicts that overshadow the potential easily solved problems, e.g. the discussion regarding domain specific IT tools vs. standardization of IT/IS that could be the center of all attention. Thirdly, the matrix does not account for the absolute importance of the problem, even though "Domain specific IT tools" are very difficult to manage from a management perspective, it is something that many designers value very high, and it can not be neglected even though it imposes large difficulties. Finally there are other underlying not outspoken needs. This could for example be that the legacy IT system in the studied company supports inter-lifecycle integration to a large extent, where interfaces towards production is close to seamless. It is difficult to get high integration on both levels, especially since the PLM suppliers' products do not support this inter-lifecycle integration to a high degree (e.g. different product platforms with limited interfaces). Hence, it is important that focus is maintained on what the company does well today, so that this is not lost in a future IS solution concept where inter-lifecycle integration that works fine today might become a problem in the future due to too much focus on interdisciplinary integration problems.

Designers stress the need for improved information exchange across engineering disciplines as one crucial improvement area, but when it comes to possible benefits with IS they only recognize personal gains. Not once did any designer reflect over the possibilities of using IS as a means for solving the need for inter-disciplinary information integration. This might be due to the designer view on systems as (relatively) isolated entities. The same contradiction, but mirrored can be discussed when looking at the situation from a management perspective. On a management level, SE integration is discussed eagerly both on top and middle management levels - though, they do not "act integration" since problems with information management are not prioritized in practice. How is it that the need for integration between departments and disciplines are recognized throughout the organization but in opposite ways? One explanation could be that designers have an actual need for integration in order to proceed in their work, but do not realize the interdependency of this need, while management discuss the need for integration strictly from a departmental outlook focusing on the intradepartmental dependency. In the latter case the need for efficient information management is not that obvious, instead other explanations for the problems can be used.

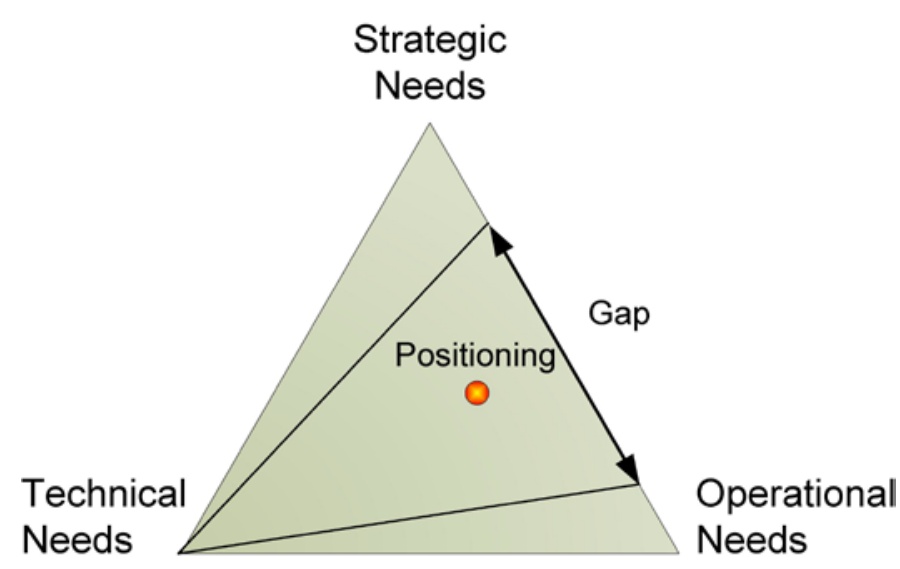

Figure 4. The figure illustrates a hypothetical gap between strategic and operational needs. Position reflects the hypothetical standpoint for a company in order to manage a trade-off between needs. 


\subsection{Balancing benefits}

Management and designers do to a large extent experience the same benefits with information management but their disability to express themselves in terms that are understood and connected to positive effects prevent synergies to arise. The matrix in Table 1 shows that in cases of conflicting needs it would be possible to make use of synergies if management use terms reflecting designer needs (green-related needs instead of red). Inabilities to understand the benefits with information management initiatives from different perspectives might result in expectancies from both management and designer perspectives parties that are difficult to achieve; Table 1 is a step towards achieving an organizational ontology regarding information management. Top management gains the possibility to base decisions on actual business needs, formulated in terms that are commonly understood throughout the company.

There is a conflict between designer and management about the expected use of standard SE processes and individual work procedures (middle pyramid in Figure 4). PLM systems should be designed to give support for formalized company processes e.g. [10], and are therefore discussed as one means to fulfill the management's perceived benefit with information management. It is also discussed that for specialized tasks or when it comes to innovative work PLM might be a means to allow the use of informal work procedures. Though, mandatory development tasks are formalized in the product development process and as long as the rules for how information should be structured are followed in the PLM systems, informal work procedures could be used. Thus, PLM systems that integrate information could be one way to accomplish support for both formalized SE processes and informal work procedures.

PLM is also seen as a means to achieve integration of distributed information. The integration requires standardized interfaces in order to work throughout the organization, which limits the use of some domain specific IT-tools, though most PLM systems, if customized, are possible to integrate with external tools [10]. It is believed that a high degree of interdisciplinary and inter-lifecycle integration will compensate for a probable lower degree of specialization. Many separated processes, and different tools and IS adapted for each process, makes it possible for each discipline to be effective in what they design. It is however argued that if there is a low degree of integration capabilities, there has to be large trade-offs to the sub-system solutions that lead to that products are suboptimized and over-designed. Hence it is more important to assure good integration and interfaces in order to "optimize" work input to an "optimal" product.

It is believed that a middle management initiative, a suggested "middle and out" approach, would focus on reaching expected designer benefits with information management. A change in methods, IT tools and systems has to be beneficial for the engineer's daily tasks in order to be accepted in the organization [6, 11, 12]. If an IS for example is not accepted or used by the designers the benefit of that system is difficult to realize [13, 14]. In the identified gaps (Figure 4) middle management has relatively large knowledge and understanding of the perceived problems from both a top and bottom-up perspective. This could also be expected since situated in the middle of the organizational connections exist both up and down in the company hierarchy. The middle out initiative has however problems in achieving complete top management support when several projects are competing for their attention. It is however believed that top management would focus on the wrong tasks if not involving middle management in the organizational change of information management. A "middle and out" approach to information system introduction is considered essential in order to bridge the identified organizational gaps.

\subsection{Allowing different goals}

The identified gap between goals (right pyramid in Figure 4) could be approached in organizations by striving for a uniform company goal with integrated information management. If this is the wanted approach, it is argued that the group that experiences practical needs with information management, namely the designers, should "dictate" what the main overall goal is. Designers discuss the need to support existing work procedures, streamline handover procedures, and ease information retrieval, thus stating operational goals. Indirectly, designers also request highly integrated IS solutions, but not at the cost of more administration and slow IS information searches and retrieval.

It is discussed that a more efficient approach to achieve integrated information management would be to allow different goals to co-exist within the organization. In cases where efforts and improvements in requirements management are made in organizations, product development will become more efficient since designers acquire e.g. enhanced configuration management and version management as well as increased traceability. The belief is that the strategic goal of reduced cost and increased quality will be achieved through the increased possibilities among designers to access qualityassured information and reduce non-value adding work. Thus, by fulfilling the operational goal the strategic goal will follow, enabling technical and organizational integration of information (Figure 5).

\subsection{Value of measur ement}

It is suggested that after having identified needs and benefits with information management the next step should be to measure the effects improvements have on efficiency in product development. It is difficult to find ways to measure key indicators for enhanced performance in information management. One feasible way is to measure collaboration and interaction effects on product development [15], another is to measure process introductions through implementation success values [16, 17]. There are also more direct behavioral ways to measure user satisfaction of IS [18]. In either case, there exists a company value with quantifying the benefits with SE process introductions. Turesson [3] states that the good intention to drive business through specific, measurable, attainable, realistic and tangible objectives tends to result in that the measurable becomes more important than what is actually important to measure. 


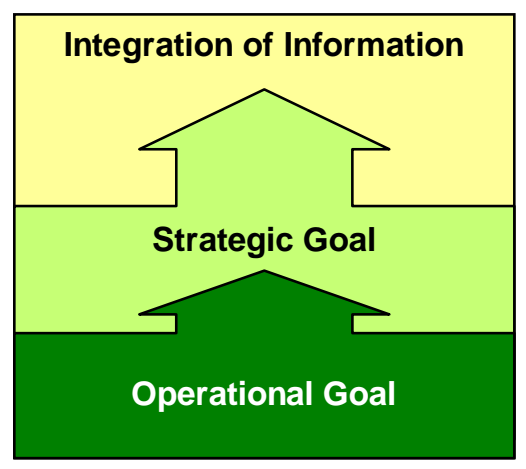

Figure 5. The different goals will align in the case where users' expectations are fulfilled and efficient information management use is obtained.

In marketing research, user satisfaction is often used as key index to measure the overall quality of a product [19]. If the same could be transferred to information management, then designer satisfaction with information management could be used as key index. It is important for top management to consider that problems might be real or imaginative, but as long as they are perceived as a problem by the designer they have to be measured as one. It is argued that companies tend to spend more money on IT infrastructure and off-the-shelf systems, than on actual company development and process support. It is believed that it is easier to persuade top management to invest in improvements on information management if the value of these investments can be measured. When performing a quantitative study with user satisfaction as the key index, other goals can be achieved as well. A questionnaire could educate the designers as well as letting them think of the different problems from different perspectives, not only their own, but other people further down the process and in other disciplines.

\section{CONCLUSIONS}

Interdisciplinary and inter-lifecycle information integration within R\&D has been explored for complex product development settings. The understanding among designers and middle management is that many of the experienced needs in product development can be connected to problems with information management. In this paper it has been shown that many of the needs expressed both from an operational perspective and a strategic perspective can be balanced, by focusing on the underlying needs, benefits and goals. It is concluded that many of the identified needs with information management and IS are common throughout the organization.

If needs are broken down and mapped towards an organizational ontology, both designers and managers will to a large extent be able to agree over benefits and goals with information management. This could be the basis of synergies with information management used to focus on issues that are shared throughout the organization. It is likely that designers' goals will align with the overall management strategic goal if efforts to solve operational needs are made in the organization. It is suggested that middle manager should act as a glue to help bridging the remaining gaps between management and designers' perspectives. It is concluded that middle management has the role to integrate different goals and strive for a middle and out explanation that fulfils both arguments and perspectives.

Large problems where trade-offs are needed do exist; being aware of the existence of these gaps as presented in this paper is believed to be the first step towards solving the problems.

\subsection{Recommendations}

- Adapt the needs in information management to the designers by e.g. structuring the information and defining abstraction levels of the information managed between engineering disciplines across the SE process lifecycle.

- Use standardized IS and focus on customizing the connected requirements.

- Employ middle and out perspective, where middle management acts to balance conflicting requirements.

- Define criteria's for information management that are measurable, connected to positive effects and that are understood throughout the organization (organizational ontology).

\section{ACKNOWLEDGEMENTS}

The authors would greatly like to acknowledge the support of VINNOVA, the Swedish Governmental Agency for Innovation Systems. The comments and suggestions of the anonymous reviewers are also appreciated.

\section{REFERENCES}

1. Kahn, K.B., Interdepartmental integration: A definition with implications for product development performance. Journal of Product Innovation Management, 1996. 13(2): p. 137.

2. Evgeniou, T. and P. Cartwright, Barriers to Information Management. European Management Journal, 2005. 23(3): p. 293-299.

3. Turesson, B. PLM from a Holistic Business Perspective. in NordPLM'06. 2006. Göteborg, Sweden.

4. Haskins, B. and J. Striegel, Integration Challenges of Complex Systems, in 16th Annual International Symposium of the International Council on Systems Engineering (INCOSE). 2006: Orlando, Florida, USA.

5. Loureiro, G., P.G. Leaney, and M. Hodgson, A Systems Engineering Framework for Integrated Automotive Development. Systems Engineering, 2004. 7(2): p. 153-166.

6. Beskow, C. and S. Ritzén, Performing changes in product development: A framework with keys for industrial application. Research in Engineering Design, 2000. 12(3): p. 172-190.

7. Bergsjö, D. and D. Malvius. Use of Information Management Systems from Designers' Perspective. in NordDesign 2006. 2006. Reykjavik, Iceland.

8. Burr, H., et al., CAx/engineering data management integration: Enabler for methodical benefits in the design process. Journal of Engineering Design 2005. 16(4): p. 385-398.

9. Malvius, D., O. Redell, and S. Ritzén. Introducing Structured Information Handling in Automotive EE Development in INCOSE 2006. 2006. Orlando, USA. 
10. Rangan, R., et al., Streamlining Product Lifecycle Processes: A Survey of Product Lifecycle Management Implementations, Directions, and Challenges. Journal of Computing and Information Science in Engineering, 2005. 5: p. 227-237.

11. Lindahl, M., Engineering Designers' Requirements on Design for Environment Methods and Tools. 2005: Doctoral Thesis in Machine Design, KTH, Stockholm.

12. Norell, M., Stödmetoder och samverkan $i$ produktutveckling : Advisory tools and co-operation in product development. Trita-MAE, 1992:7. 1992, Doctoral Thesis in Machine Design, Royal Institute of Technology, Stockholm.

13. Ottersten, I. and M. Balic, Effektstyrning av IT. 2004: Liber AB.

14. Sutinen, K., G. Gustafsson, and J. Malmqvist. Computer support for requirements management in an international product development project. 2004. Salt Lake City, UT, United States: American Society of Mechanical Engineers, New York, NY 100165990, United States.
15. Kahn, K.B., Market orientation, interdepartmental integration, and product development performance. Journal Of Product Innovation Management, 2001. 18(5): p. 314-323.

16. Knippel, E. and A. Schulz. Quantifying the Benefit of Introducing Systems Engineering Processes - Myth or Reality? in 16th Annual international Symposium on the International Conference on Systems Engineering (INCOSE) 2006. Orlando, Florida, USA.

17. Börjesson, A. and L. Mathiassen, Successful Process Implemenation. IEEE Software, 2004.

18. Lee, Y.-L., S.-L. Hwang, and E.M.-Y. Wang, An Integrated Framework for Continuous Improvement on User Satsifaction of Information Systems. Industrial Management and Data Systems, 2006. 106(4): p. 581-595.

19. Kristensen, K. and J. Eskildsen, Design of PLS-based Satisfaction Studies

2006, Aarhus School of Business, Center for Corporate Performance: Aarhus V, Denmark. 